\title{
A study of functional outcome of arthroscopic rotator cuff repair in rotator cuff tear patients
}

\author{
Vamsinath $\mathbf{P}^{1, *}$, Madan Ballal ${ }^{2}$, T. H. Prakashappa ${ }^{3}$, Sathish Kumar $^{4}$ \\ ${ }^{1,4}$ Junior Resident, ${ }^{2}$ Associate Professor, ${ }^{3} \mathrm{HOD}$, Dept. of Orthopaedics, Sanjay Gandhi Institute of Trauma and Orthopedics, \\ Bangalore, Karnataka, India
}

*Corresponding Author:

Email: vamsi.nath2001@gmail.com

\begin{abstract}
Introduction: Even though mini-open rotator cuff repair is still commonly performed, and results are comparable to arthroscopic repair, all-arthroscopic repair of rotator cuff tear is now fast becoming a standard care for rotator cuff repair. The purpose of the study was to evaluate the functional outcome of arthroscopic rotator cuff repair in rotator cuff tear patients.

Materials and Methods: This prospecutive study included 22 cases of rotator cuff tear patients of either sex fitting the inclusion criteria at the orthopedic department of Sanjay Gandhi Institute of Trauma and Orthopedics, Bangalore from September 2016 to December 2017. Patients included were between 18 to $70 \mathrm{yrs}$ of age with MRI proven rotator cuff tear who underwent all arthroscopic rotator cuff repair and willing to participate in study. Exclusion criteria included associated shoulder lesions, revision rotator cuff repair, irreparable tears, acj arthritis and rotator cuff tear arthropathy. Patients admitted with MRI proven Rotator cuff tear after meeting the inclusion and exclusion criteria are selected for the study. They will undergo detailed history, clinical and radiological evaluation. Arthroscopic rotator cuff repair by single row or double row technique using suture anchors by a single trained surgeon. Postoperative rehabilitation as per standard protocol. Postoperative evaluation done at, 3rd month, 6th month and 1 year. Range of motion, UCLA and ASES scoring done at preoperative and postoperative follow-ups.

Results: A Prospective study with 22 patients is undertaken to study the functional outcome of Arthroscopic rotator cuff repair. The mean age in our study is 53.5 years majority are in the age group 40 to $60 \mathrm{yrs}$. Out of 22 patients, 13 were male, 9 were female. Major part of our study contained partial thickness tears $(59.1 \%)$ rather than full thickness tears $(40.9 \%)$. 81.8 \% (18) patients in our study had traumatic tears and $18.2 \%$ (4) patients had degenerative tears. There is significant improvement of flexion from $126.8^{\circ}$ preoperatively to $147.0^{\circ}$ postoperatively at 1 year, abduction from $125.3^{\circ}$ to $149.5^{\circ}$, external rotation from $51.1^{\circ}$ to $80.2^{\circ}$, internal rotation from $40.45^{\circ}$ to $67.5^{\circ}$. In our study according to UCLA score, out of 22 patients, 3 patients had poor outcome, 7 patients had average outcome, 8 patients had good outcome and 4 patients had excellent outcome. Mean UCLA score increased from 9.09 preoperatively to 28.50 postoperatively at the end of 1 st year.

Conclusion: Arthroscopic rotator cuff repair is as good as mini open repair in outcome. Advantages of arthroscopic rotator cuff repair include, less postoperative pain, small scar and ability to diagnose other shoulder pathologies. Patients need preoperative phy siotheraphy to achieve good range of motion before surgery for better final outcome.
\end{abstract}

Keywords: Rotator cuff, Functional outcome, Arthroscopic.

\section{Introduction}

Rotator cuff tears are common cause in patients complaining shoulder pain. The rotator cuff undergoes progressive degenerative changes with increasing age and may lead to partial tear of cuff and finally to complete rupture of the rotator cuff. The spectrum of these disorder ranges from inflammation to massive tearing of the rotator cuff musculotendinous unit. Rotator cuff repair is the one of the most frequent procedures performed in the shoulder joint. Surgical treatment of chronic rotator cuff tears is indicated when non operative treatment fails. The techniques of rotator cuff repair have evolved from traditional open repair, to arthroscopically assisted mini-open rotator cuff repair (MRCR), to complete arthroscopic rotator cuff repair (ARCR). Though mini open rotator cuff is commonly performed in many centres, arthroscopic rotator cuff repair is now becoming standard surgery for rotator cuff tear. ${ }^{1}$ arthroscopic techniques are now used to repair even large tears and also to mobilize retracted tears. Arthroscopic repair match open and mini open repair in results and also helps in thorough evaluation of joint thereby increasing diagnostic value of procedure.
Arthroscopic technique is a less invasive approach which may have advantageous for postoperative rehabilitation and outcome. The study is meant to evaluate the functional outcome of arthroscopic rotator cuff repair in rotator cuff tear patients.

\section{Materials and Methods}

Source of Data: This prospecutive study included 22 cases of rotator cuff tear patients of either sex fitting the inclusion criteria at the Orthopedic Department of Sanjay Gandhi Institute of Trauma and Orthopedics, Bangalore from September 2016 To December 2017. Patients included were between 18 to $70 \mathrm{yrs}$ of age with MRI proven rotator cuff tear who underwent all arthroscopic rotator cuff repair and willing to participate in study. Exclusion criteria included as sociated shoulder lesions, revision rotator cuff repair, irreparable tears, acj arthritis and rotator cuff tear arthropathy.

\section{Methodol ogy}

Patients admitted with MRI proven rotator cuff tear after meeting the inclusion and exclusion criteria are 
selected for the study. They will undergo detailed history, clinical and radiological evaluation. Clinical examination includes range of motion, empty can test, belly press test, external rotation stress test, neer's impingement test, Hawkins test, speed test and yergason's test. With prior informed consent, a preoperative anesthetic evaluation is done. Arthroscopic rotator cuff repair by single row or double row technique using suture anchors by a single trained surgeon. Post operative rehabilitation as per standard protocol. Postoperative evaluation done at, 3rd month, 6th month and 1year. Range of motion, UCLA and ASES scoring done at preoperative and postoperative follow-ups.

Data Analysis: To examine continuous variables Arithmetic mean, standard deviation, Chi square test, Pearson's correlation and t-tests were used. Paired t-test were used to compared Pre-operative and postoperative UCLA scores, ASES scores and Rom. One way ANOVA was also used to compare more than two variables

Surgical Technique: Same technique followed for all patients. Patients kept in beach chair position under General anesthesia. Three standard portals are used during arthroscopic rotator cuff repair (anterior, lateral subacromial, posterior). After arthroscopic inspection and treatment of the glenohumeral joint, the arthroscope is introduced into the subacromial space through the posterior portal, and a lateral subacromial portal is established. An anterior portal is also established for inflow and as a working portal. Before assessing and classifying the rotator cuff tear, all bursal and fibrofatty tissue must be debrided from the margins of the rotator cuff. The tear size and pattern were evaluated and the mobility and reparability of the torn cuff were estimated. Inverted mattress suture is made through the tendon with fibretape suture using suture passer. Both limbs of fibretape Suture are loaded into the Suture Anchor eyelet using the attached threader loop. Driver handle is gently tapped to create bone socket and swivelock sp suture anchor is inserted until the anchor body contacts bone.it is rotated in clockwise direction until the anchor body is flush with the bone. Tip retention suture is unwrapped and pulled it out. Fibertape tails are cut with an open-ended fibertape suture cutter. More anchors are used in same manner when large tears are present. Partial thickness tears are usually repaired in a single row fashion after converting into full thickness tear.

Postoperative Management: Same postoperative rehabilitation protocol followed for all patients. Extremities were immobilized in a sling for 6 weeks. During the initial 6 weeks, only pendulum exercises was allowed followed by gentle active exercises after 6 weeks deltoid and biceps strengthening after 8 weeks. Scapular stabilization exercises allowed after 12 weeks. Patients returned to normal activity and work after 4 to 6 months.

\section{Results}

A Prospective study with 22 patients is undertaken to study the functional outcome of Arthroscopic rotator cuff repair. The mean age in our study is 53.5years. Majority are in the age group 40 to 60yrs. Out of 22 patients, 13 were male, 9 were female. Major part of our study contained partial thickness tears $(59.1 \%)$ rather than full thickness tears (40.9\%). $81.8 \%$ (18) patients in our study had traumatic tears and $18.2 \%(4)$ patients had degenerative tears. There is significant improvement of flexion from $126.8^{\circ}$ preoperatively to $147.0^{\circ}$ postoperatively at 1year, abduction from $125.3^{\circ}$ to $149.5^{\circ}$, external rotation from $51.1^{\circ}$ to $80.2^{\circ}$, internal rotation from $40.45^{\circ}$ to $67.5^{\circ}$. In our study according to UCLA Score, out of 22 patients, 3 patients had poor outcome, 7 patients had average outcome, 8 patients had good outcome and 4 patients had excellent outcome. Mean UCLA score increased from 9.09 preoperatively to 28.50 postoperatively at the end of $1^{\text {st }}$ year. Mean ASES score improved from 22.53 preoperatively to 86.60 postoperatively

Table 1: Range of movements

\begin{tabular}{|c|c|c|c|c|c|c|}
\hline $\begin{array}{c}\text { Range of } \\
\text { movements }\end{array}$ & Pre op & At 3 months & At 6 months & At 1 year & $\begin{array}{l}\text { Preop - } \\
\text { 1year }\end{array}$ & $P$ value \\
\hline Flexion & $126.81^{\circ} \pm 8.66^{0}$ & $140.68^{0} \pm 11.47^{0}$ & $145.90^{\circ} \pm 10.98^{0}$ & $147.04^{0} \pm 12.59^{0}$ & $20.23^{0}$ & $<0.001^{* *}$ \\
\hline Abduction & $125.36^{\circ} \pm 10.64^{\circ}$ & $140.00^{\circ} \pm 13.36^{\circ}$ & $144.31^{\circ} \pm 12.08^{\sigma}$ & $149.54^{0} \pm 12.43^{\circ}$ & $24.18^{0}$ & $<0.001 * *$ \\
\hline $\begin{array}{l}\text { External } \\
\text { Rotation }\end{array}$ & $51.14^{0} \pm 4.61^{0}$ & $62.27^{0} \pm 5.28^{0}$ & $71.36^{0} \pm 7.74^{0}$ & $80.23^{0} \pm 3.61^{0}$ & $29.09^{0}$ & $<0.001 * *$ \\
\hline $\begin{array}{l}\text { Internal } \\
\text { Rotation }\end{array}$ & $40.45^{0} \pm 4.33^{0}$ & $54.32^{0} \pm 5.83^{0}$ & $61.82^{0} \pm 3.94^{0}$ & $67.50^{\circ} \pm 4.56^{0}$ & $27.05^{0}$ & $<0.001 * *$ \\
\hline
\end{tabular}

Table 2: UCLA total score distribution of patients studied

\begin{tabular}{|l|c|c|}
\hline Total Score & No. of patients & \% \\
\hline $0-20$ (poor) & 3 & 13.7 \\
\hline $21-27$ (average) & 7 & 31.8 \\
\hline $28-31$ (good) & 8 & 36.3 \\
\hline $32-35$ (excellent) & 4 & 18.2 \\
\hline
\end{tabular}


Table 3: Difference of UCLA and pair wise significance

\begin{tabular}{|l|c|c|c|}
\hline Difference & $\begin{array}{c}\text { UCLA At } \\
\text { presentation }-\mathbf{3} \\
\text { Months }\end{array}$ & $\begin{array}{c}\text { UCLA At } \\
\text { presentation }-\mathbf{6} \\
\text { Months }\end{array}$ & $\begin{array}{c}\text { UCLA At presentation - } \\
\mathbf{1} \text { year }\end{array}$ \\
\hline Mean \pm SD & $-09.91 \pm 2.81$ & $-15.59 \pm 4.54$ & $-19.41 \pm 4.83$ \\
\hline P value & $<0.001 * *$ & $<0.001 * *$ & $<0.001 * *$ \\
\hline
\end{tabular}

Table 4: Difference of ASES and pair wise significance

\begin{tabular}{|l|c|c|c|}
\hline Difference & $\begin{array}{c}\text { ASES At presentation } \\
\mathbf{- 3} \text { Months }\end{array}$ & $\begin{array}{c}\text { ASES At presentation } \\
\mathbf{- 6} \text { Months }\end{array}$ & $\begin{array}{c}\text { ASES At presentation } \\
-\mathbf{1} \text { year }\end{array}$ \\
\hline Mean \pm SD & $-46.16 \pm 09.42$ & $-55.10 \pm 10.83$ & $-64.07 \pm 12.24$ \\
\hline P value & $<0.001 * *$ & $<0.001 * *$ & $<0.001^{* *}$ \\
\hline
\end{tabular}



Fig. 1: Range of movements

Flex, Flexion; ABD, Abduction; ER, External rotation; IR, Internal rotation

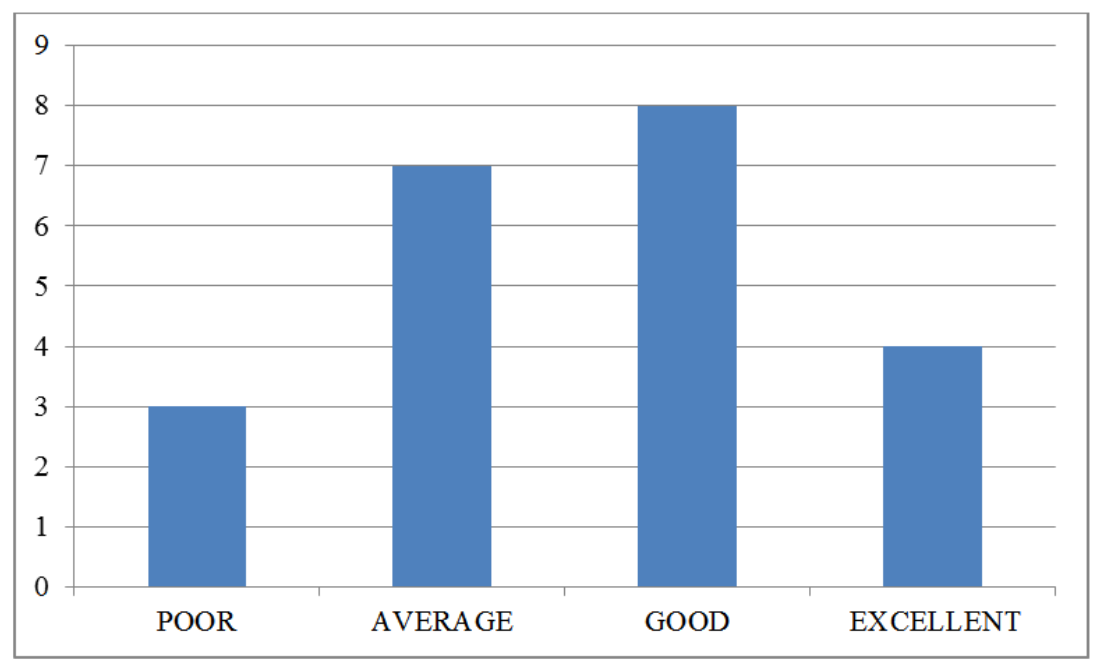

Fig. 2: UCLA Total Score distribution of patients studied

\section{Discussion}

In this study, majority were in the age group

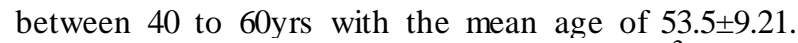
Similarly studies conducted by Sugaya et al, ${ }^{2}$ Park et $\mathrm{al}^{3}{ }^{3}$ Brian. Cole et al, ${ }^{4}$ Burks et $\mathrm{al}^{5}$ also had mean age of 57.7yrs, 57yrs, 57yrs, 56yrs respectively.
In our study, age of the patient was not found to be a significant factor which affects the clinical outcome of the rotator cuff repairs. Similar observations were made by Bennet WF et al, ${ }^{6}$ Stollsteimer and Savoie et $\mathrm{al}^{7}$ One reason why age has not found to have any major affect in our series could be because of mean age less than 60 years. This group is known to have good outcome after cuff repair. However, if age exceeds 
more than 70 years, the results could have been poorer or age would have shown it affect over the outcome. Age has been proved to be the most important predictor of clinical and radiological outcomes after the rotator cuff repair, as age is a predictor of tissue viability, and therefore, probably predicts success of cuff repair. Many studies have shown that the success of cuff repair decreases with advancing age especially after 65 years, and retear rates may be higher after 65 years. Millar et $\mathrm{al}^{8}$ reported that mean ASES score and range of motion is better in arthroscopic repair than open repair. Tauro 9 reported lesser hospital stay, small scar, less postoperative pain in arthroscopic group compared to open repair.

In the present study, majority of tears are traumatic tears. Patients with degenerative tears have decreased outcome and range of motion compared to traumatic tears. Very little work has been done in this regard. Braune et $\mathrm{al}^{12}$ in 2003 had stated traumatic tears to have a better outcome than the degenerative tears.

On the basis of histological investigations, ${ }^{13}$ partial tears extend over time and will be converted to full thickness tears, arthroscopic repair is best for partial tears. In our study, we had 9 full thickness tears and 13 partial thickness tears. We found no significant change in final outcome between partial or full thickness tear. Comparing our study to one more similar study where both partial and full thickness tears were treated arthroscopically by single row technique. The study was conducted by Karin S Peters ${ }^{14}$ at St. George Hospital where they have assessed the patients by ASES shoulder scoring system pre operatively and at 6 months. They hypothesized that partial thickness tear has higher incidence of retears and shoulder stiffness compared to full thickness group. At 6 months follow up they found there was no statistical significance. Park et al. ${ }^{15}$ and Deutsch et al. ${ }^{16}$ reported significant increase in shoulder scores in arthroscopic repair.

There is significant improvement of flexion from $126.8^{\circ}$ preoperatively to $147.0^{\circ}$ postoperatively at $1 \mathrm{yr}$, abduction from $125.3^{\circ}$ to $149.5^{\circ}$, external rotation $51.1^{\circ}$ to $80.2^{\circ}$, internal rotation $40.45^{\circ}$ to $67.5^{\circ}$. In the study conducted by Cole et $\mathrm{al}^{4}$ and Alberto $\mathrm{N} \mathrm{M}^{17}$ et al also showed significant increase in flexion, abduction and rotations at the end of follow up. We observed patients with degenerative tears have less improvement in range of motion compared to traumatic tears. Adequate postoperative rehabilitation programs are determinant to obtain good recovery in terms of range of motion, muscle strength, and function. We followed initiation of passive range of motion from postoperative day one in our patients and achieved better range of motion.

In our study out of 22 patients, 3 patients had poor outcome, 7 patients had average outcome, 8 patients had good outcome and 4 had excellent outcome.

In this review they have analyzed the rotator cuff tears depending on technique and post operative UCLA and ASES were analyzed. They found no significance in outcome of patients treated by both techniques which was similar to our study results. The patients in the analysis were mostly in age group 51-60 which was also seen in our study group. We were not able to compare between the techniques in our study as the most of the cases were single row and comparison cannot be done due to inadequate cases in group operated by double row technique.

One other study where post op function assessed by Ganesh Kamath et al $^{18}$ at Barnes - Jewish Hospital and pre operative and post operative ASES results were analysed.

The mean age in both studies is around 51-60 years and pre op and post operative ASES results were analyzed and found to be statistically significant. Similarly Burks et al., $\mathrm{S}$ W Khoo et al, ${ }^{19}$ Cole et al, Sugaya et $\mathrm{al}^{2}$ had similar results as our study.

In one other study conducted by Christopher $\mathrm{K}$ Jones and Felix H. Savoie ${ }^{20}$ at the southern center for Orthopedics and sports medicine, Georgia a retrospective study was conducted on patients who were operated for massive and large tears by arthroscopy and assessed by UCLA shoulder scoring system. They found at end of study that $88 \%$ of patients had good to excellent results with 6 patients having failed but in our study $54 \%$ had good to excellent results according to UCLA scoring system. As three dimensional evaluation of a tear is possible with arthroscopy, specific repair for specific tear can be done. Pain, function and range of motion have shown significantly good improvement in our study which had lead to significant patient satisfaction. Patient was able to do all daily routine activities like combing hair, dressing, after getting satisfactory range of motion. There were no infections and neurovascular injuries reported. 4 patients had postoperative shoulder stiffness who continued physiotheraphy and nsaids for long time. No re surgery has been done for any patient.

The limitations of the study include less sample, less follow up period and lack of randomization.

\section{Conclusion}

1. Arthroscopic rotator cuff repair is as good as mini open repair in outcome

2. Advantages of arthroscopic rotator cuff repair include, less postoperative pain, small scar and ability to diagnose other shoulder pathologies .

3. There is no difference in functional outcome between partial and full thickness tear treated arthroscopically.

4. Patients need preoperative physiotheraphy to achieve good range of motion before surgery for better final outcome

5. Adherence to strict post operative physiotherapy is key for achieving full range of movement and pain free activities of daily living. Age, sex, type of tear do not affect the post-operative result, but a larger clinical trial would be needed to prove the same. 
6. Patients with degenerative tears and especially elderly woman will have less satisfactory outcome compared to patients with traumatic tears and young age.

\section{References}

1. Vivek P, Jaap Willems W. Rotator cuff tear: A detailed update, Asia-Pacific Journal of Sports Medicine, Arthroscopy, Rehabilitation and Technology, 2;(2015):114.

2. Sugaya H, Maeda K, Matsuki K, Moriishi J.Functional and structural outcome after arthroscopic full-thickness rotat or cuff repair: single-row versus dual-row fixation. Arthroscopy 2005 Nov;21(11):1307-16.

3. Park JY, Lhee SH, Choi JH, Park HK, Yu JW, Seo JB. Comparison of the clinical out comes of single-and double-row repairs in rotator cuff tears. Am J Sports Med. 2008;36(7):1310-6.

4. Brian JC, Pearce M, Richard W K, Winslow A, Paul B. $\mathrm{L}$, Jennifer $\mathrm{KH}$ et al. Arthroscopic rotator cuff repair: Prospective functional out come and repair integrity at minimum 2-year follow-up Journal of Shoulder and Elbow Surgery jse.2006.12.011.

5. Burks RT, Crim J, Brown N, Fink B, Greis PE:A Prospective Randomized Clinical Trial Comparing Arthroscopic Single-and Double-Row Rotator Cuff Repair. Am J Sports Med. 2009 Apr;37(4):674-82.

6. Bennett WF. Arthroscopic repair of full-thickness supraspinatus tears (smallto-medium): a prospective study with 2-to 4-year follow-up. Arthroscopy: The Journal of Arthroscopic \& Related Surgery. 2003;19(3):249-56.

7. Stollsteimer GT, Savoie 3rd FH. Arthroscopic rotator cuff repair: current indications, limitations, techniques, and results. Instructional course lectures.1997;47:59-65.

8. Millar NL, Wu X, T antau R, Silverstone E, Murrell GA. Open versus two forms of arthroscopic rotator cuff repair. ClinOrthopRelat Res. 2009;467(4):966-978.

9. Tauro JC. Arthroscopic rotator cuff repair: Analysis of technique and results at 2- and 3-year follow-up. Arthroscopy 1998;14:45-51.

10. Kim SH, Ha KI, Park JH, Kang JS, Oh SK: Arthroscopic versus mini-open salvage repair of the rotator cuff tear: outcome analysis at 2 to 6 year's follow-up. Arthroscopy 2003 Sep;19(7):746-754.

11. Galatz, L M, Ball, Craig M F, Teefey, Sharlene A M, William D, Yamaguchi, Ken. Completely Arthroscopically Repaired Large and Massive Rotator Cuff Tears JBJS, 2004;86(2):219-224.

12. Braune C, von Eisenhart-Rothe R, Welsch F, Teufel M, Jaeger A. Mid-term results and quantitative comparison of postoperative shoulder function in traumatic and nontraumatic rotator cuff tears. Arch Orthop Trauma Surg. 2003;123(8):419-24.

13. Hamada $\mathrm{K}$, Tomonaga $\mathrm{A}$, Gotoh $\mathrm{M}$, et al. Intrinsic healing capacity and tearing process of torn supraspinatus tendons: in situ hybridization study of alpha 1 (I) procollagen mRNA. J Orthop Res. 1997;15:24-32.

14. Peters, Karin S.; McCallum, Sebastian; Briggs, Lisa; Murrell, George A. C. A Comparison of Outcomes After Arthroscopic Repair of Partial Versus Small or MediumSized Full-Thickness Rotator Cuff Tears. Journal of Bone \& Joint Surgery, American Volume. 2012;94(12):10781085.

15. Park JY, Chung KT, and Yoo MJ. A serial comparison of arthroscopic repairs for partial and full-thickness rotator cuff tears. Arthroscopy.2004;20:705-11.
16. Deutsch A. Arthroscopic repair of partial-thickness tears of the rotator cuff. J Shoulder Elbow Surg. 2007;16:193201.

17. Alberto N M; Marcelo F, Pedro D S, Luciana Andrade da Silva. Evaluation of the results from arthroscopic repair on rotator cuff injuries among patients under 50 years of age Rev Bras Ortop. 2011;46(3):276-80.

18. Kamath, Ganesh, Galatz, Leesa M. Keener, Jay D, Teefey, Sharlene, Middleton, William, Yamaguchi, Ken. Tendon Integrity and Functional Outcome After Arthroscopic Repair of High-Grade Partial-Thickness Supraspinatus Tears. JBJS. 2009,91;5:1055-1062.

19. SW Khoo, MS (Ortho), SM Khoo, MS (Ortho), YK Yeong, MS (Ortho), B Towil, MS (Ortho)Functional Outcome After Arthroscopic Rotator Cuff Repair - An Early Experience Malaysian Orthopaedic Journal;2009:32.

20. Christopher K. Jones, Felix H. Savoie Ii. Arthroscopic Repair of Large and Massive Rotator Cuff Tears Arthroscopy: The Journal of Arthroscopic and Related Surgery, Vol 19, No 6 (July-August), 2003:pp 564-571. 